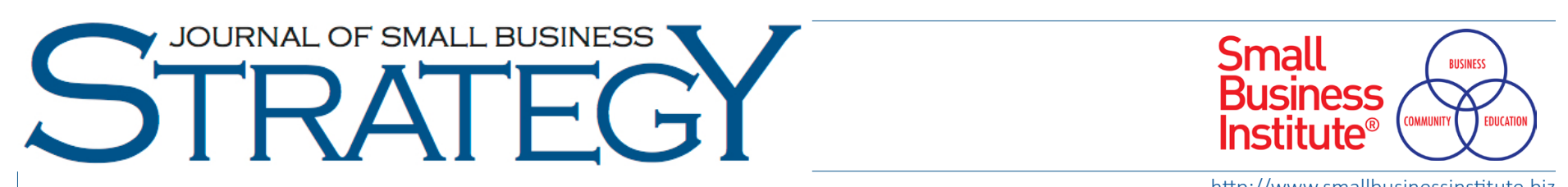

http://www.smallbusinessinstitute.biz

\title{
Two sources of overconfidence: Incorporating disconfirming feedback in an entrepreneurial context*
}

\author{
Mark Simon ${ }^{1}$, John Kim² \\ ${ }^{1}$ University of Michigan - Flint, marksimo@umflint.edu \\ 2Oakland University, kim@oakland.edu
}

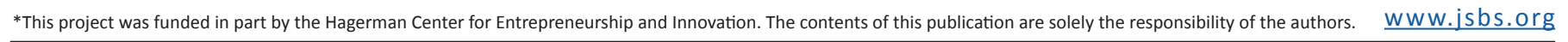
Keywords:

Overconfidence, Belief revision, Entrepreneur, Information processing

\begin{abstract}
The prevalence of overconfidence when making entrepreneurial decisions has led some scholars to argue that it has positive ramifications while others to disagree. The question is: Will highly overconfident individuals who consider starting a venture be willing to correct initial misconceptions? We found that it depends upon the source of overconfidence. Even at equally high overconfidence levels, individuals who reached that level by intentionally processing additional evidence were less likely to revise erroneous beliefs when compared to those with a natural tendency toward high overconfidence. In contrast to the overconfidence source, overconfidence level was not associated with changing incorrect beliefs.
\end{abstract}

\section{Introduction}

"... the thing that scares me most is someone who is convinced they are right, because they will never change." (Furr, Cavarretta, \& Garg, 2012)

Many might agree with the statement above, especially when it refers to someone who is highly confident about incorrect information. This paper, however, introduces a crucial but overlooked distinction that may strongly influence whether highly overconfident individuals will persist with mistaken beliefs. Overconfidence is a cognitive bias that occurs when individuals express a degree of certainty in their judgments that exceeds the accuracy of those judgments (Klayman, Soll, González-Vallej, \& Barlas, 1999). Overconfidence occurs at different levels. High overconfidence refers to being extremely certain of an incorrect answer, such as being $99 \%$ sure one is correct. Mild overconfidence happens when an individual believes an incorrect fact is correct but may be only $51 \%$ certain that he or she has the right answer. Being highly confident (i.e., $95 \%$ confident) of a correct answer is not considered overcon-

Journal of Small Business Strategy

2017, Vol. 27 No 03, 9-24

ISSN: 1081-8510 (Print) 2380-1751 (Online)

CCopyright 2017 Small Business Institute ${ }^{\circledR}$ fidence. Since the answer is correct, the individual's confidence does not exceed his or her accuracy.

High overconfidence plays a critical role in entrepreneurship (Forbes, 2005; Zacharackis \& Shepherd, 2001). This bias has been associated with a slew of entrepreneurial decisions, such as whether to introduce pioneering products (Simon \& Houghton, 2003), to acquire funding (Forbes, 2005), or to commercialize inventions (Astebro, Jeffrey, \& Adomdza, 2007). The current study focuses on whether or not to start a new company, a decision that has been associated with overconfidence (Robinson \& Marino, 2015).

Although high overconfidence is associated with entrepreneurial actions, scholars disagree about its performance ramifications (Hayward, Shepherd \& Griffin, 2006; Trevelyan, 2008). Some (e.g., Simon \& Houghton, 2003) claim this bias will lead to poorer results, arguing it is linked to over-entry into new markets, to excessive investments, and to commitment to risky projects with disappointing results. Researchers have even asserted that overconfidence is "pernicious" (Barnes, 1984), "the single most catastrophic judgment error one can make" (Griffin \& Varey, 1996). They fear that this bias will lead people to fail to react to new information if it contradicts their current beliefs (Forbes, 2005). This, in turn, might cause individuals to become rig- 
id, hampering their ventures long after founding (Forbes, 2005).

In contrast to the above scholars, Busenitz and Barney (1997) argue that overconfidence may be beneficial in entrepreneurial settings. Likewise, Simon, Kim, Houghton, and Deng (2011) have asserted that more confident managers of small firms achieve greater success when introducing products. These scholars maintain that this bias launches individuals into actions that will generate needed, real-time feedback, which is salient enough to correct initial misconceptions.

At the core of the debate about the consequences of overconfidence is a crucial, unresolved question (Furr et al., 2012). Will highly overconfident individuals revise their initial beliefs after receiving disconfirming feedback? Our answer is complex, depending, in part, upon how these people became highly overconfident. High overconfidence arises from one of two very general sources (Forbes, 2005). First, individuals "naturally" may be more prone to high overconfidence (Klayman et al., 1999). This suggests that as soon as they consider assumptions regarding a proposed new venture, they will be highly, but erroneously, confident that their assumptions are correct. These naturally overconfident people are unlikely to intentionally process additional information because they are already certain they are correct.

In contrast, some individuals initially may be mildly overconfident. To increase their confidence before proceeding, they may intentionally process additional information (e.g., studying secondary data) (Simon et al., 2011). Yet, for a host of reasons (Barnes, 1984; Kahneman \& Lovallo, 1993), the information they seek may make them more confident of their incorrect assumptions rather than leading them to the correct answer. As such, they could reach as high a level of overconfidence as that of the "naturally" overconfident group.

Different types of searches for evidence influence cognitive flexibility (McMillan \& White, 1993), suggesting a person's path to high overconfidence may affect how open she or he is to revising beliefs after encountering disconfirming feedback. Our research question, therefore, asks: At equal levels of overconfidence, are individuals who intentionally and recently process additional information less likely to change their beliefs when compared to those who have not? The importance of answering this question is bolstered by an editorial in Journal of Business Venturing that marked its 30-year anniversary (Shepherd, 2015). In the article, editor Dean Shepherd argued that examining how initial entrepreneurial beliefs are refined when exposed to stakeholders represents a major future direction that can expand the boundaries of entrepreneurship research. This is the exact goal of the current study.

\section{Literature Review}

Research has suggested multiple potential causes of high overconfidence. For example, people may engage in wishful thinking, overestimate their abilities, rely on misleading cues, double-count redundant information, and reach firm conclusions from samples that are too small (Barnes, 1984; Oskamp, 1965; Robinson \& Marino, 2015; Simon \&Houghton, 2003). Additionally, some people just may be predisposed to such bias (Soll, 1996).

At a broader level, high overconfidence develops through one of two sources. Those following the first path are "naturally" more overconfident than others (Forbes, 2005; Klayman et al., 1999). This may occur because overconfidence has trait-like tendencies (Forbes, 2005; Klayman et al., 1999; Soll, 1996); certain people consistently express greater overconfidence in their information, regardless of the topic or question.

This tendency is reasonably stable across time and situation and may stem from relatively unchanging factors, such as long-standing habits (Yates, Lee, Shinotsuka, Patalano, \& Sieck, 1998), firmly established cognitive customs (Yates et al., 1998), and established personality types (Soll, 1996). In multiple studies (e.g., Klayman et al., 1999; Mahajan, 1992), highly overconfident subjects who answered dozens of questions spent only seconds providing answers to each question. These findings suggest that their overconfidence was automatic. Given that naturally overconfident individuals start the process certain they are correct, they have little reason to invest effort into revisiting their answers (Tan, Tan, \& Teo, 2012). They do not engage in processing additional information; they just know. Overconfidence via this path is a relatively effortless, immediate, top-of-the-mind subconscious phenomenon. We refer to overconfidence arising in this way as Natural Overconfidence (NOC).

Those following the second route initially may be mildly overconfident about facts that are critical to the success of an entrepreneurial endeavor (Hayward et al., 2006). However, in situations where people are not very confident, they may strive to become more confident by employing more complex and thorough judgment processes that require greater cognitive effort (Anderson \& Maletta, 1999). In other words, they begin processing additional evidence (Brinckmann, Grichnik, \& Kapsa, 2010). They might analyze information, develop plans, scrutinize secondary data, and perform surveys (Brinckmann et al., 2010; Simon et al., 2011). As they examine more data, their confidence grows (Jonas, Schulz-Hardt, Frey, \& Thelen, 2001). All else being equal, this increased confidence is probably appropriate.

There are many reasons, however, why processing additional evidence may not result in a better understanding 
of the topic, especially in entrepreneurial settings where available information is often irrelevant or inaccurate (Kahneman \& Lovallo, 1993). Making important decisions in "murky" environments not only causes individuals to search more but also to search in biased ways (Davidsson \& Wahlund, 1992). Kahneman and Lovallo (1993) suggest that extensive planning effort can lead individuals to pay too much attention to a plan's hypothetical conclusions and too little attention to what usually occurs. In a similar vein, a seminal study by Oskamp (1965) found that psychologists became more confident in their incorrect clinical decisions when they expended more effort studying redundant patient information. Furthermore, Kiesler and Sproull (1982) have argued that given total limits on cognitive capacity, processing more evidence may lead to constructing illusory correlations and false analogies.

Collectively, these findings suggest that the entrepreneurs' intense efforts to process more information may lead to a high level of overconfidence because it boosts confidence without increasing accuracy. Ultimately, the overconfidence level of those processing more information may equal the overconfidence level of the NOC group. We refer to overconfidence arising from intentionally processing additional information as Processing-Evidence Overconfidence (POC).

There are, of course, other patterns related to search and confidence. Instead of initial overconfidence, individuals may be confident of the correct conclusions. Also, mildly overconfident individuals may abandon their venture idea or conduct a search that corrects their initial misperceptions. But with that said, a multitude of scholars (e.g., Busenitz \& Barney, 1997; Forbes, 2005; Houghton, Simon, Aquino, \& Goldberg, 2000; Kahneman \& Lovallo, 1993; Mahajan, 1992; Robinson \& Marino, 2015) have argued that patterns associated with POC and NOC occur frequently and have important implications for startups, making POC and NOC worthy of study.

Despite the distinct nature of POC and NOC, no one has examined whether the two differentially influence the extent to which individuals will revise their beliefs when faced with feedback that indicates their high overconfidence is incorrect. While many studies have examined the general tendency for overconfidence to persist in the face of new questions (e.g., Mahajan, 1992), no overconfidence research has explored the likelihood of changing an initial conclusion, even though flexibility is critical to entrepreneurial success (Blank, 2013).

Changing an initial conclusion is often referred to as belief revision (Nickerson, 1998). One's ability to adjust his or her belief after encountering disconfirming feedback is not only crucial to success but also difficult to achieve (Nickerson, 1998). The ability to do so tends to vary greatly depending upon a number of factors (Haynie, Shepherd, \& Patzelt, 2012). One factor in particular that may influence belief persistence is confirmation bias (Nickerson, 1998).

Confirmation bias occurs when people seek or interpret evidence in ways that support existing beliefs and is perhaps the best known and most widely accepted inferential error to come out of the literature on human reasoning (Nickerson, 1998). Some (e.g., Haynie et al., 2012) argue that in select situations, confirmation bias may be helpful. However, in many other situations, it may be the single most problematic aspect of human reasoning (Nickerson, 1998).

We are particularly interested in the tendency for individuals to persist in a belief when faced with a disconfirming expert opinion. The tendency to listen to or ignore experts is one of life's basic decisions (Soll \& Larrick, 2009). Furthermore, several scholars (e.g., Mannes, 2009; Yaniv, 2004) have asserted that people do not give as much weight to expert opinion as is appropriate and have called for more research in this area.

Confirmation bias is especially likely to occur when considering facts related to deciding whether or not to start a venture (Comegys, 1976). We argue that a multitude of interrelated characteristics of POC, as compared to NOC, may increase confirmation bias during the new venture decision. This decreases one's willingness to revise beliefs even in the face of disconfirming expert opinion. Figure 1 displays underlying black-boxed dynamics that reflect the progression of confirmation bias and belief revision for POC and NOC. The paragraphs that follow explain the figure and develop our hypotheses.

Most typically, individuals seeking to build their confidence in a fact gradually add subsequent pieces of evidence to previous ones (Jonas et al., 2001). As such, POC individuals will gather evidence sequentially over time (Anderson \& Maletta, 1999), whereas NOC individuals demonstrate natural high overconfidence, suggesting they will not intentionally process additional evidence (Soll, 1996). Anderson and Maletta (1999) as well as Nickerson (1998) have argued that a sequential process increases confirmation bias. As Figure 1 indicates, individuals start the search by seeking and finding one piece of supporting evidence (Nickerson, 1998). But after finding one piece of support, the tendency to look for others is exacerbated, increasing the confirmation bias. In other words, their belief that their original assumption is correct grows as does their tendency to ignore a disconfirming expert opinion (McMillan \& White, 1993). In this way, the confirmation bias snowballs and strengthens.

Also, sequential search increases the amount of time one spends evaluating the decision (Higgins, 1996). This fosters readiness to view information in a way that is con- 


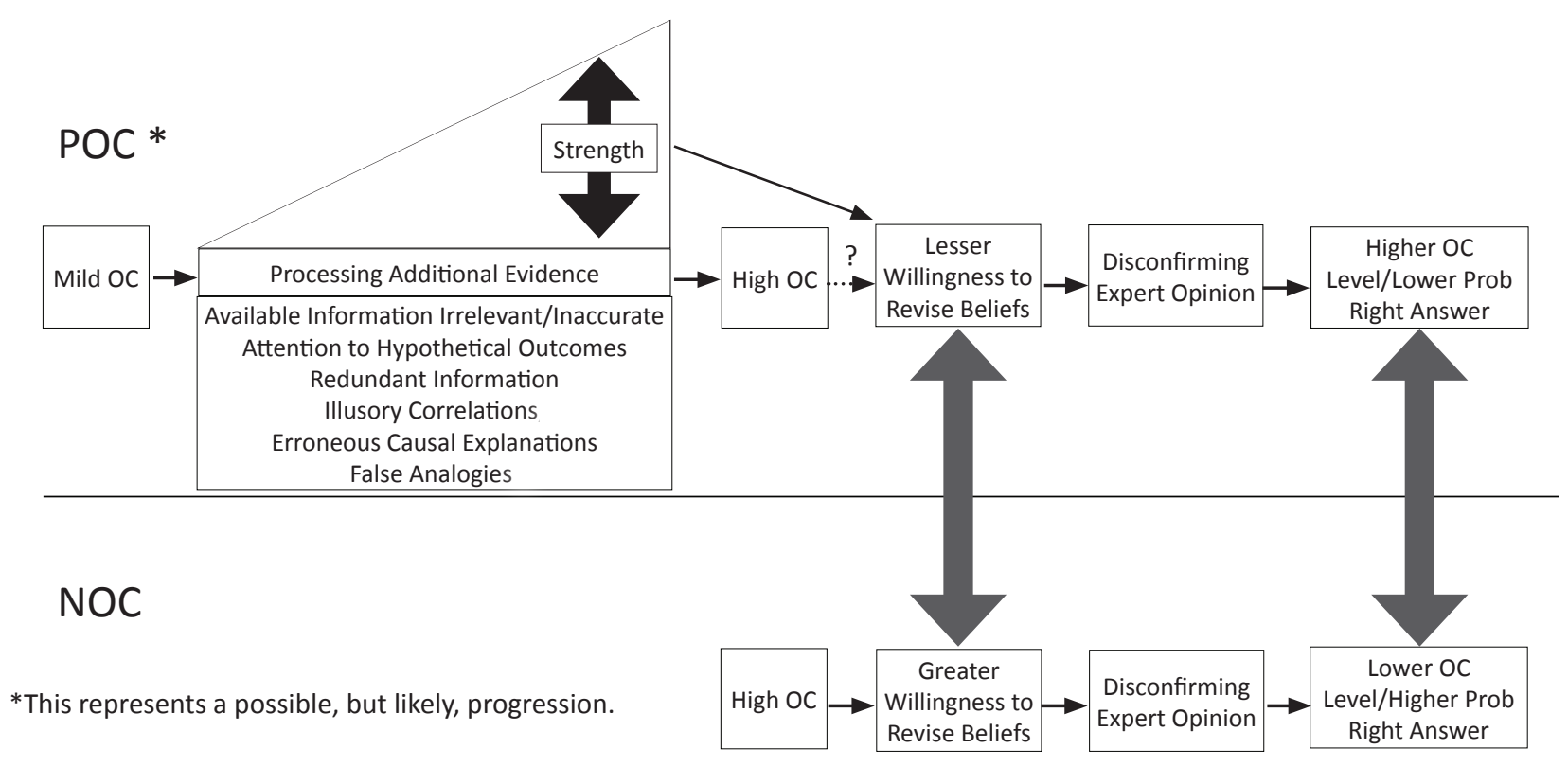

Figure 1. Model of progression for POC and NOC.

sistent with prior beliefs, recalling attention to the original hypothesis (Nickerson, 1998). Repeatedly thinking about a hypothesis increases commitment to the prior decision, causing individuals to feel like they no longer need more information to make the decision (Jonas et al., 2001).

In addition to gathering evidence sequentially, POC individuals will have gathered it recently, suggesting they will recall not only their conclusion but also their specific reasons for reaching it (Anderson \& Maletta, 1999). In contrast, when NOC individuals recall past conclusions, even ones about which they are still highly confident, they are unlikely to remember the original reasons for those conclusions (Ashton \& Ashton, 1990). Given this shakier foundation, decision makers are more likely to revise their beliefs should they be presented with a disconfirming expert opinion. Alternatively, individuals who are highly confident and remember the reasons for their confidence are much less likely to change their beliefs.

The POC individual's intentional information processing through action involves more effort than the NOC individual expends. Effort makes information more salient and accessible, that is, easier to retrieve from memory (Wyer, 2008). Furthermore, the accessibility of the original information will hinder the retrieval and evaluation of alternative information (Wyer, 2008) even if the alternative information is more appropriate. Similarly, exerting effort increases the individual's belief in the diagnosticity and validity of evidence (Kardes, Kim, \& Lim, 1994). These characteristics often lead decision makers to ignore or downplay disconfirming feedback. Given the above, Anderson and Maletta's (1999) argument that effort increases confir- mation bias and reduces willingness to alter a conclusion is not surprising.

Interestingly, Lau and Coiera's (2006) research has indicated that information search patterns have an effect independent of, and as strong as, confidence level on belief revision. Similarly, Jonas and colleagues (2001) have determined that commitment to a choice was distinct from confidence in a choice and that the former had the greater effect on belief revision.

In the context of the current study, revising one's belief entails lowering confidence in a wrong conclusion or increasing the likelihood of changing an incorrect conclusion to a correct one. Thus, Hypotheses 1 and 2 follow.

Hypothesis 1. Even at equal levels of overconfidence, when faced with a disconfirming expert opinion, individuals exhibiting POC are less likely to change their incorrect answers than those exhibiting NOC.

Hypothesis 2. Even at equal levels of overconfidence, when faced with a disconfirming expert opinion, individuals exhibiting POC lower their confidence in incorrect answers by smaller increments than those exhibiting NOC.

The next hypothesis explores the relationship between individuals' initial overconfidence level and the decrease in that level after being told they are wrong by an expert. Some scholars (e.g., Fischhoff, Slovic, \& Lichtenstein, 1977; Hayward et al., 2006) assume that the higher the initial overconfidence level, the less it will drop. Scholars have not empirically tested this assumption and may have overlooked other factors (Astebro et al., 2007). We believe the 
higher the initial overconfidence level, the greater the drop, which is the opposite of what they assume.

Russo and Schoemaker's (1992) study of overconfidence tentatively supports our assertion. Although the study's participants were highly confident $(90 \%)$ that each of their incorrect answers was correct, they paradoxically expected, in the aggregate, to get over half the questions they answered wrong, but did not know which ones. Given their recognition that many of the answers about which they were highly confident were wrong, it follows that if faced with evidence contradicting an individual conclusion, their confidence in it may drop. At the other end of the spectrum, a finding by Astebro and colleagues (2007) provides insight about mildly overconfident individuals. The study found that these individuals did not significantly change their positive conclusion even after receiving a negative assessment by experts. This may suggest that they did not substantially decrease their initial mild overconfidence level.

We believe two dynamics support our belief that higher initial levels of overconfidence are associated with a greater decrease in that overconfidence when faced with disconfirming feedback. The first relates to the salience of evidence. The more salient the disconfirming evidence, the more likely it will be used to revise decisions (Dane, 2010). We argue that higher initial overconfidence levels make disconfirming feedback more salient. For example, 99\% overconfident individuals will be quite surprised to later encounter any disconfirming feedback. Thus, the feedback will be salient and likely to dramatically lower their confidence. In contrast, those who are $51 \%$ confident are almost expecting to find contradictory evidence and are unlikely to make a large adjustment.

The second dynamic relates to the idea that some individuals have a greater tendency to easily and strongly react to evidence that led to their higher initial overconfidence (Klayman et al., 1999). This tendency to significantly respond to information may also affect them when they later receive a disconfirming expert opinion, thereby resulting in a large adjustment (Ashton \& Ashton, 1990). In contrast, it may be that some individuals are initially only mildly overconfident because of a tendency to treat evidence with skepticism (Klayman et al., 1999). These individuals may, therefore, make smaller adjustments when they encounter disconfirming expert opinion. Collectively, these arguments lead to Hypothesis 3:

Hypothesis 3. The higher an individual's level of confidence in an incorrect answer, the greater the degree the individual will lower that confidence after encountering a disconfirming expert opinion.

The dynamics supporting Hypothesis 3 may apply less for POC than for NOC. The first dynamic is that the greater one's overconfidence level, the more salient the disconfirming expert opinion. However, the information POC individuals used to increase their confidence before a disconfirming expert opinion was quite salient because they expended effort and engaged in a sequential process (Higgins, 1996; Nickerson, 1998). Using the saliency of that information as a base line, the later disconfirming expert opinion might seem less salient even if one is at a high level of confidence. Therefore, the disconfirming expert opinion may have a lesser tendency to decrease one's confidence level.

The second dynamic indicates that individuals tend to become highly overconfident because they strongly react to information (Ashton \& Ashton, 1990), suggesting that their high confidence level will drop substantially after a disconfirming expert opinion. This dynamic may, however, apply much less to POC individuals. By definition, they do not reach high levels of confidence by strongly reacting to information but instead increase their confidence only after seeking multiple pieces of evidence and building a case (Ashton \& Ashton, 1990; Nickerson, 1998). As such, they may be less likely to react strongly when they come across one piece of evidence in the form of a disconfirming expert opinion. Therefore:

Hypothesis 4. When faced with disconfirming expert opinion, the relationship between higher levels of confidence and greater decreases in that level will be less in magnitude for POC individuals than for NOC individuals.

\section{Method}

We tested these hypotheses using 163 Master of Business Administration (MBA) students and Executive MBAs who attend a Midwestern university. Similar to research by Haynie et al. (2012) and Simon, Houghton, \& Aquino (2000), we asked subjects to "assume the role" of an entrepreneur. In response to information from a teaching case, students had to decide whether or not to start a new venture. The new venture constituted entering a market by introducing an Internet marketing software. Students were provided information about the industry, risk, and potential of the new venture. Critical components in the decision to start a new venture were the development cost and the size of the current and future market, which were not presented in the case.

Scholars have used teaching cases to study issues in entrepreneurship similar to those in the current paper, including examining confirmation bias when investing in a developing country (Jonas et al., 2001) and capturing simplified information processes used to cope with problematic product lines (Walsh, 1995). 
Mirroring the approach of Houghton et al. (2000), Simon et al. (2000), and Robinson and Marino (2015) among others, we conducted a correlation study in a tightly controlled setting rather than an experiment or a field study to examine biases and the decision to start a venture. Consistent with other studies of the confirmation bias (e.g., Anderson \& Maletta, 1999; Lau \& Coiera, 2006), we captured belief revision by comparing answers and confidence level before receiving disconfirming feedback with final answers and confidence level after receiving the feedback. We also followed the lead of others (e.g., Harvey \& Fischer, 1997; Yaniv, 2004) by measuring disconfirming feedback in the form of a disconfirming expert opinion.

Broadly speaking, our approach was to separate individuals into two groups, the first of which (the NOC group) was instantly and effortlessly highly confident of its incorrect answers (i.e., 99\% confident). In contrast, the second group (the POC group) was initially only mildly confident of its incorrect answers (i.e., 55\% confident). We then had the POC group process misleading evidence that increased its confidence in the incorrect answer to equal that of the NOC group. Both groups then read that an expert told them their answer was incorrect. Finally, we compared the extent to which each group changed its answer based upon that statement.

Importantly, while we required mildly overconfident individuals to process additional information, processing additional information was not an experimental treatment. In other words, we were not testing whether processing increased confidence. We took this as a given (and were correct). Instead, we had mildly overconfident individuals process information to raise their overconfidence, so we could compare their reaction to that of the NOC group. We did not start the process with similar groups, as required in an experimental design, because doing so would not relate to our research question. Our question examined whether two initially different groups would differ in their reaction to a stimulus, namely a disconfirming expert opinion. We discuss each of the study's steps in more detail below and capture them in Table 1.

\section{Steps in Study}

Step 1: Measure OC. In step one, participants logged on to a website, provided background information, and read a teaching case that focused on whether to launch a new venture that would sell self-service Internet marketing software. The decision to start a new venture is fundamental to entrepreneurship research (Simon et al., 2000).

We captured subjects' overconfidence after they read the case. Student responses to cases about startup have been used to uncover important findings related to entrepreneurship, especially findings related to cognitive biases
(Houghton et al., 2000; Robinson \& Marino, 2015; Simon et al., 2000). In our study, subjects answered three questions and indicated how confident they were in their answers. For instance, we asked them whether the international Internet growth rate from March of 2007 to March of 2008 was less than 300 million new users worldwide or more than 350 million new users. By way of example, a respondent might have answered the question by selecting more than 350 million new users (the wrong answer) and indicated he or she was $90 \%$ confident in this choice. The correct answer was not contained in the case, and at this point, none of the subjects processed additional evidence before responding, literally providing answers within seconds of reading the questions.

Step 2: Form NOC and POC groups. To form groups, we first discarded answers that were correct, as they did not reflect overconfidence. We then divided the subjects into a NOC and a POC group for each of the three questions. We split the responses for each question at the median, based on the subjects' level of confidence in an incorrect answer. The NOC group was composed of individuals who answered incorrectly and displayed higher levels of initial confidence. For example, NOC subjects may have been $98 \%$ certain of their incorrect belief that the Internet grew by more than 350 million new users. To form the POC group, we selected those individuals who answered incorrectly and initially displayed only mild confidence in their incorrect answer about Internet growth (e.g., 53\% overconfidence).

Step 3: Measure OC before a disconfirming expert opinion. For the NOC group, we used the measure of initial overconfidence developed in step one to capture the group's overconfidence before a disconfirming expert opinion. This group's initial overconfidence level met the study's requirements in that group members had high overconfidence without engaging in processing additional information, so we did not need to make any adjustments. We did, however, need to take an additional step to form the POC group because it had not yet considered new evidence that would boost overconfidence and had a lower level of overconfidence than that of the NOC group. As such, we could not examine the hypotheses that, at equal levels of overconfidence, the two groups would react differently to a disconfirming expert opinion.

To make the subjects in the POC group consider additional evidence that would raise their overconfidence, we had them read and/or analyze additional information related to the questions they previously answered. Although we provided accurate data, we selected data and required analysis that would generate misleading results and make the subjects more confident of their initial incorrect answer. Take, for example, POC subjects who initially were only 
Table 1

Steps in Design

\begin{tabular}{l|l|l}
\hline Steps & \multicolumn{2}{l}{ NOC: Task } \\
\hline Step 1: Measure OC & $\begin{array}{l}\text { Subjects indicate answers and confidence in those answers to fact-based ques- } \\
\text { tions. }\end{array}$ \\
\hline $\begin{array}{l}\text { Step 2: Form NOC \& POC } \\
\text { groups }\end{array}$ & $\begin{array}{l}\text { We split sample at medi- } \\
\text { an, placing those with high } \\
\text { initial overconfidence in NOC } \\
\text { group. }\end{array}$ & $\begin{array}{l}\text { We split sample at median, placing those with mild } \\
\text { initial overconfidence in POC group. }\end{array}$ \\
\hline $\begin{array}{l}\text { Step 3: Measure OC before a } \\
\text { disconfirming expert opinion. }\end{array}$ & $\begin{array}{l}\text { Not relevant. We used the } \\
\text { data from step 1. }\end{array}$ & $\begin{array}{l}\text { Subjects search by completing a series of tasks } \\
\text { that makes them more confident of their incorrect } \\
\text { conclusion. }\end{array}$ \\
$\begin{array}{l}\text { Step 4: Form matched pairs \& } \\
\text { subjects read a disconfirming } \\
\text { expert opinion }\end{array}$ & $\begin{array}{l}\text { We placed subjects into pairs, comprised of one member of the NOC group and } \\
\text { one member of the POC group. We formed the pairs to make sure the two sub- } \\
\text { jects' overconfidence levels (before a disconfirming expert opinion) were equal. } \\
\text { and assign confidence levels for the questions } \\
\text { asked in step 1. }\end{array}$ \\
$\begin{array}{l}\text { Then subjects from both groups read that an expert had indicated their answer } \\
\text { was incorrect. }\end{array}$ \\
$\begin{array}{l}\text { Step 5: After disconfirming } \\
\text { opinion, capture overconfi- } \\
\text { dence \& change in answer and } \\
\text { confidence level }\end{array}$ & $\begin{array}{l}\text { After subjects have received a disconfirming opinion, they give new answers and } \\
\text { confidence to the questions asked in step 1. } \\
\text { We compare overconfidence before a disconfirming expert opinion (step 3) to } \\
\text { overconfidence after a disconfirming expert opinion. }\end{array}$ \\
\hline
\end{tabular}

$53 \%$ confident in their incorrect answer that the Internet grew by more than 350 million people. We had them read that Internet traffic more than doubled every four months during some periods in the '90s and that from 2006 to 2008 Internet usage grew by over $80 \%$ within China's population of 1.2 billion people. After reading this type of accurate but misleading information and performing some related calculations, we asked subjects their new conclusion about Internet growth and their confidence in that conclusion. The exercise caused many of the initially mildly overconfident subjects to become highly overconfident, often ultimately equaling the overconfidence level of the NOC subjects. We labeled their new conclusions and confidence level as their overconfidence before disconfirming expert opinion.

Step 4: Form matched pairs and provide a disconfirming expert opinion. Next, we placed subjects into matched pairs. We formed the pairs to include one member of the NOC group and one member of the POC group who were at equal levels of overconfidence before a disconfirming expert opinion for a given answer. But in some cases, more than one member of the POC group matched the confi- dence level of a member of the NOC group or vice versa. In these cases, we formed the pairs by probing deeper. We developed the final matches to make sure they were closest on, not just level of overconfidence but also optimism and experience, as both could also influence belief revision (Astebro et al., 2007; Dane, 2010). This procedure ensured that the POC group, as compared to the NOC group, processed additional evidence and that both groups ultimately were at equal levels of overconfidence.

After forming the pairs, we provided both groups with a disconfirming expert opinion by having them read that a knowledgeable individual suggested their answer was incorrect. For example, after answering the Internet-related question, subjects read, "You launched the web marketing software, and sales were less than expected. You mention to a friend whom you consider quite knowledgeable in this area that you are surprised by the low sales, especially considering that you believe there were over 350 million new users of the Internet from March 2007 to March 2008. Your friend mentions that a year ago he conducted research on Internet usage and is almost sure that there were fewer than 300 million new users during that period." 
Step 5: After a disconfirming opinion, capture overconfidence and change. Immediately after receiving a disconfirming opinion from an expert, we gave the subjects the opportunity to change their answers and/or their confidence in their answers to develop the respondents' final overconfidence level. We then compared these answers and confidence levels to their answers and confidence levels before they read the disconfirming expert's opinion. Because each member of a matched pair had identical confidence levels before the expert opinion, we knew differences in the two groups' confidence level could not generate the results.

\section{Measures}

We collected data reflecting overconfidence, processing evidence, and four control variables. We present the specific measures in Appendix A.

Overconfidence. There are several types of overconfidence, including overconfidence in skills, in current knowledge, and in predictions of the future (Astebro et al., 2007; Simon \& Shrader, 2012). Each, however, has different underlying dynamics, antecedents, occurrence rates, and/or performance ramifications (Griffin \& Varey, 1996; Simon \& Shrader, 2012). This study focused on one type of overconfidence, namely knowledge overconfidence (Busenitz \& Barney, 1997). Knowledge overconfidence occurs when individuals express a degree of certainty in their judgments about current objective information that exceeds the accuracy of those judgments (Simon \& Shrader, 2012). It is important to research this form of overconfidence because it is especially relevant to entrepreneurship (Busenitz \& Barney, 1997; Forbes, 2005), ubiquitous (Russo \& Schoemaker, 1992), studied by researchers more than any other form (Klayman et al., 1999), and critical for decision making (Klayman et al., 1999).

Entrepreneurship, of course, involves more than assessing current objective information. Entrepreneurs often enact their environments and may need information that becomes available only through marketplace actions. However, being correct about objective information is also important (Sykes \& Dunham, 1995). It seems reasonable to contend that all things being equal, more often than not entrepreneurs' successes depend upon their ability to race for a viable opportunity before depleting their resources (Blank, 2013). Given this, we believe one can make a compelling case that entrepreneurs usually are better off relying on initially correct information, rather than initially incorrect information. Therefore, like many entrepreneurship scholars (e.g., Busenitz \& Barney, 1997; Forbes, 2005; Keh, Foo, \& Lim, 2002; Robinson \& Marino, 2015) who have studied overconfidence, our measures reflect factual information.
Consistent with other research (e.g., Busenitz \& Barney, 1997; Forbes, 2005), we measured knowledge overconfidence by asking subjects to respond to questions that had clear-cut right and wrong answers, but the answers were not contained in the case. For each of the three questions we posed, we provided two possible responses and informed subjects that one of the two was correct.

Overconfidence has two components: confidence level and accuracy. After choosing one answer for each question, the subjects recorded how confident they were that their answers were correct on a scale ranging from $50 \%$ to $100 \%$. They would not put down less than $50 \%$ because that would suggest they should have selected the other choice. A response of $50 \%$ indicated that they thought their response was a total guess, while $80 \%$ would indicate that they believed there was an eight-in-ten chance they chose the correct answer.

We then measured "accuracy" for each question, coding answers as "100\%" correct if the answer was right and "0\%" correct if it was wrong. Finally, to determine the extent to which the person was overconfident (or underconfident) for each question, we subtracted the accuracy score from his or her confidence level score; the greater the difference, the greater the overconfidence. For example, someone who was $99 \%$ confident in an incorrect answer ( $0 \%$ correct) would have been $99 \%$ overconfident.

NOC vs POC Membership. For members of the POC group, we measured $O C$ three times: 1 ) immediately after they read the case, 2) after they processed new evidence but before the disconfirming expert opinion, and 3) after the disconfirming expert opinion (i.e., final $\mathrm{OC}$ ). For the NOC groups, we measured OC only twice because the measure after reading the case was that same as before the disconfirming expert opinion. In other words, they did not process new evidence to change it.

We assigned a " 0 " to the NOC group to indicate that its members did not process additional information before receiving the disconfirming expert opinion, and a " 1 " to the $\mathrm{POC}$ group to indicate that its members did.

Dependent Variables. The first dependent variable in the study was change in choice. We assigned " 0 " to individuals who did not change their erroneous answer before an expert opinion to the correct answer after an expert opinion (their final answer) and " 1 " to individuals who shifted to the correct answer.

The second dependent variable, change in confidence level in the incorrect answer, indicated the degree to which subjects' confidence level in the incorrect answer before the disconfirming expert opinion changed after they received the disconfirming expert opinion. Change in confidence level equaled their confidence level in the incorrect 
answer before the disconfirming opinion minus their confidence level in the incorrect answer after the opinion.

Control Variables. The study also included four control variables. The first was optimism, given that it might influence willingness to change conclusions (Astebro et al., 2007). We measured optimism by taking the average score of six items. Cronbach's alpha for this scale was .79. We also controlled for experience because it can affect one's level of overconfidence (Mahajan, 1992) and willingness to change conclusions (Astebro et al., 2007; Dane, 2010). We captured experience in two different ways. First, we asked subjects the extent to which they had work experience related to new product introductions or web marketing. They responded on a 1 to 5 Likert scale, ranging from "None" to "An Extremely Large Extent." The second question asked how many college-level courses they took related either to new product development or to web marketing. Given that the questions reflected two different domains, work and educational experience, we did not combine responses but instead included each separately in our analysis.

Finally, we examined the subjects' entrepreneurial intent. Specifically, we first instructed subjects to assume they were the entrepreneur considering launching the venture. To measure entrepreneurial intent, we next asked whether Anduro Marketing should launch, using a scale ranging from $1=$ "Definitely not" to $5=$ "Definitely yes." It was important to control for entrepreneurial intent given that individuals who consider starting a venture generally display greater overconfidence than others (Robinson \& Marino, 2015). More specifically, scholars (e.g., Robinson \& Marino, 2015) found that students who decided to start the venture described in a teaching case exhibited greater levels of overconfidence.

\section{Analysis}

To rule out sources of extraneous variation, we checked to ensure that the two groups were not different on several variables, such as confidence before expert opinion, optimism, experience, management level, time in the master's program, educational concentration, gender, and desire to start a venture. All $p$ values fell between .50 and .80 , indicating that the groups were not significantly different on these variables.

Each subject responded to three questions, but we excluded correct responses from our analysis as these did not reflect overconfidence. Given these exclusions, each participant generated from one to three usable responses. For overconfidence question one, which asked about growth in use of the Internet, there were 68 subjects, 34 in each group. For the second question, which addressed budget overruns, there were 82 subjects, with 41 each in the POC and NOC groups. The final question related to percentage of companies with websites. There were 54 subjects, 27 in each group. Since overconfidence level may depend upon the specific question asked, we did not combine the subjects' overconfidence on each question but instead allowed the distinct effect of each to influence our results.

Hypothesis 1 posits that individuals exhibiting POC versus NOC less frequently will change to the correct answer when faced with a disconfirming expert opinion. We conducted a logistical regression to test the hypothesis, using a model that included the source of overconfidence (POC and NOC), the overconfidence before expert opinion, and the four control variables (i.e., work experience, course experience, optimism and entrepreneurial intent).

In conducting the regression analysis, we first corrected for intragroup correlation because multiple observations existed from the same respondent. For example, he or she may have answered all three questions. Multiple observations from the same respondent may bias the standard errors and lead to spurious findings for variables of interest (Moulton, 1990). We accounted for the intragroup correlation using the Moulton correction method (Moulton, 1990) by clustering respondents who provided multiple responses and running a regression model. There were 202 observations with 134 clusters. The standard error was adjusted for the clusters.

Hypotheses 2, 3, and 4 propose that change in level of confidence after expert opinion is a function of the source of overconfidence (POC versus NOC), the level of overconfidence before an expert opinion, and the interaction between the source of overconfidence and the level of overconfidence before the opinion, respectively. We analyzed these hypotheses using regression, again correcting for the intragroup correlation using the Moulton correction method.

\section{Results}

Table 2 presents the means, standard deviations, and correlations among the study variables. The number of observations was 202, and the standard error was adjusted for 134 clusters in the observations. The correlations in the table among independent variables all have an absolute value well under .50, suggesting a relative absence of multicollinearity (McNamara \& Bromiley, 1997). All VIF scores were within acceptable parameters, never exceeding 2.00.

Hypothesis 1, which posits that individuals exhibiting POC versus NOC will less frequently change to the correct answer when faced with a disconfirming expert opinion, was supported. Results presented in Table 3 indicate that the overall model was significant (Wald value $=47.43 ; p$ $<.001)$ as was the effect of the overconfidence source ( $\beta=$ -2.67; $p<.001)$. The control variables were not significant. 
Results for Hypotheses 2, 3, and 4 are shown in Table 4. The equation was significant ( $\mathrm{F}=10.71, p<.001)$. In support of Hypothesis 2, we found that individuals exhibiting POC, as compared to those exhibiting NOC, lowered their confidence less $(\beta=-28.06 ; p<.001)$. Consistent with $\mathrm{Hy}$ pothesis 3 , individuals with a higher initial level of overconfidence lowered their confidence level more after encountering a disconfirming expert opinion $(\beta=.43, p<.05)$. Finally, as predicted in Hypothesis 4, the interaction of the source of overconfidence and the overconfidence before the opinion was significant $(p<.05)$ and in the hypothesized direction $(\beta=-.80)$. In other words, the overconfidence level before the disconfirming expert opinion had less of an influence on the change in overconfidence level for POC individuals than for NOC individuals. The four control variables were not significant.

\section{Discussion}

The prevalence and controversial nature of overconfidence has led entrepreneurship scholars to theorize about its consequences (e.g., Busenitz \& Barney, 1997; Hayward et al., 2006). Some argue that its ramifications may be positive, speculating that those who consider starting a new venture will be able to correct early misconceptions (e.g., Busenitz \& Barney, 1997). Others, however, believe the opposite (Hayward et al., 2006). To shed light on this debate, we empirically explored the connection between overconfidence and belief revision. In so doing, we contributed to the literature in four ways. First, this study provides insight into what facilitates belief revision. Researchers (e.g., Nicholls-Nixon, Cooper, \& Woo, 2000; Parker, 2006) assert that many entrepreneurial tasks, including starting companies and launching innovative products, require modifying ini- tial conclusions. Yet adjusting beliefs is often difficult, and the failure to do so is ubiquitous, leading scholars to call for more research in this area (Nicholls-Nixon et al., 2000; Parker, 2006). More specifically, Subbotin (1996) has suggested that scholars need to study the link between confidence and belief revision, asserting that this relationship is understudied.

In response, the current study focused on one form of confidence, namely overconfidence. Researchers have argued, but have not tested, the belief that the higher the overconfidence, the less individuals will revise their beliefs if they receive disconfirming feedback (Fischhoff et al., 1977; Simon et al., 2003). Our study's results not only suggest that this is not the case but also indicate that the reverse may be true. We found that the higher the individual's overconfidence level, the more (not less) they will lower that level when faced with a disconfirming expert opinion. We also found that highly overconfident individuals, as opposed to mildly overconfident individuals, were not significantly less likely to change initial answers.

The current study also contributed to the literature by identifying factors that might influence whether overconfidence has positive or negative ramifications. Several studies have theorized that the environment (Simon \& Shrader, 2012), stage of venture (Busenitz \& Barney, 1997), or type of initiative (Simon \& Houghton, 2003) might influence the consequences of overconfidence. We introduced a new factor, processing information. Equally important, our study, unlike previous ones, empirically examined these proposed relationships.

The remaining contributions expand our understanding of several theories, such as clarifying the relationship between the escalation of commitment to a failing course of action and belief revision. Escalating commitment re-

Table 2

Means, Standard Deviations and Correlations

\begin{tabular}{|c|c|c|c|c|c|c|c|c|c|}
\hline & Mean & s.d. & 1 & 2 & 3 & 4 & 5 & 6 & 7 \\
\hline 1. Change in Con. level & 22.50 & $(29.22)$ & & & & & & & \\
\hline 2. Change in Choice & .32 & $(.47)$ & $.90^{* *}$ & & & & & & \\
\hline 3. Processed Evidence & .50 & $(.50)$ & $-.48^{* *}$ & $-.50^{* *}$ & & & & & \\
\hline 4. OC before Exp. Opinion & .86 & $(7.62)$ & $.10^{*}$ & -.06 & .00 & & & & \\
\hline 5. Optimism & 3.87 & $(.83)$ & .00 & .02 & .08 & -.03 & & & \\
\hline 6. Ent. Intention & 3.42 & $(.94)$ & .09 & $.09^{t}$ & $-.10^{\mathrm{t}}$ & .02 & -.02 & & \\
\hline 7. Work Experience & 2.29 & (1.06) & .06 & .04 & -.08 & $.14^{*}$ & $-.24^{* *}$ & .07 & \\
\hline 8. Course Experience & 1.07 & (1.15) & .05 & .03 & -.04 & $.10^{\mathrm{t}}$ & $.19^{* *}$ & $.09^{t}$ & $.18^{* *}$ \\
\hline
\end{tabular}

${ }^{\mathrm{t}} p<.10, * p<.05, * * p<.01$

Number of observations $=202$ (Standard Error adjusted for 134 clusters in observations)

All probabilities are one-tailed given that the hypotheses were directional 
flects a behavior, namely continuing an action, whereas belief revision captures a cognitive process. POC might lead to belief rigidity, which in turn leads to continued failing actions.

This research provides a deeper grasp of overconfidence. Research has determined that there are different types of overconfidence, each which has different antecedents and consequences (Trevelyan, 2008). No other study, however, has examined whether the process by which an individual becomes overconfident matters. This omission is critical because studies focus on one process yet implicitly assume their findings will generalize to overconfidence reached through a different process. Our results suggest this may not be the case.

\section{Limitations}

Despite these novel contributions, the reader should recognize the study's limitations. First, we utilized Master of Business Administration (MBA) students, although this choice is justifiable because MBAs frequently have maturity in business situations (Schwenk, 1995). Limitations also stemmed from the project's design. We conducted a correlation study in a tightly controlled setting rather than a field study because field studies are more prone to sources of extraneous variation and noise (Schwenk, 1995). Forego-

Table 3

Logistic Regression Results Using Moulton Correction Method for Change in Answer

\begin{tabular}{lc}
\hline & Coefficient \\
\hline $\begin{array}{l}\text { Dependent Variable } \\
\quad \text { Changed in Choice }\end{array}$ \\
\hline Independent Variables: & $-2.67^{* * *}$ \\
$\quad$ Source of Overconfidence & -.02 \\
Overconfidence Before Expert Opinion & .06 \\
Work Experience & .00 \\
Educational Experience & .24 \\
Optimism & .16 \\
$\quad$ Entrepreneurial Intent & $47.43^{* * *}$ \\
\hline Wald value
\end{tabular}

$* p<.05, * * * p<.001$

Number of observations $=202$ (Standard Error adjusted for 134 clusters in observations).

All probabilities are one-tailed given that the hypotheses were directional.

Table 4

Regression Results Using Moulton Correction Method for Change in Overconfidence Level

\begin{tabular}{lc}
\hline Variables & Coefficient \\
\hline Dependent Variable & \\
$\quad$ Changed in Overconfidence Level & \\
Independent Variables: & $-28.06^{* * *}$ \\
Source of Overconfidence & $.43^{*}$ \\
Overconfidence Before Expert Opinion & $-.80^{*}$ \\
Interaction of Source of Overconfidence \& Overconfidence Before Expert Opinion & .34 \\
Work Experience & .07 \\
Educational Experience & 2.01 \\
Optimism & .78 \\
Entrepreneurial Intention & $10.71^{* * *}$ \\
\hline F-value &
\end{tabular}

$* p<.05, * * * p<.001$

Number of observations $=202$ (Standard Error adjusted for 134 clusters in observations)

All probabilities are one-tailed given that the hypotheses were directional. 
ing a field study, however, could limit the extent to which findings apply to the natural environment. We minimized this potential pitfall by using a teaching case that reflected the complexity of an entrepreneur's decision context (Zacharackis \& Shepherd, 2001) and measured overconfidence on the type of facts that individuals actually use when deciding whether to start a new venture (Mahajan, 1992).

\section{Implications for Future Research}

This study could potentially spur intriguing future research. Scholars may wish to examine the extent to which the relationships among entrepreneurial passion, search, and rigidity might have dynamics similar to the ones among overconfidence, search, and rigidity. Examining passion in this context can be especially beneficial given its central role in entrepreneurship, its similarity to overconfidence, its relationship to increased effort, and its potential to generate the confirmation bias (Gielnik, Spitzmuller, Schmitt, Klemann, \& Frese, 2015). Overconfidence research may also benefit by examining cases where individuals were initially correct or cases in which decision makers started with incorrect beliefs that they corrected through study. It also could focus on cases in which individuals are mildly, rather than highly, overconfident immediately before receiving an expert opinion.

Perhaps the most controversial aspect of either NOC or SOC is whether individuals who process additional evidence will become more overconfident. We fully realize that sometimes they won't. This said, there are many reasons why they might. For example, information in entrepreneurial settings is often misleading, and processing more evidence can lead to illusory correlations (Kiesler \& Sproull, 1982), erroneous causal explanations (Kiesler \& Sproull, 1982) and redundant evidence (Oskamp, 1965), all of which can increase overconfidence. Most importantly, confirmation bias suggests that after forming a tentative incorrect hypothesis about a fact, individuals will seek out information to validate rather than to refute it.

\section{Implications for Practice}

This study's findings have several implications. For decades, educators, consultants, and scholars have told entrepreneurs to formulate a detailed plan based upon their study of multiple factors. Our results, however, suggest this process could enhance confirmation bias, making it difficult for entrepreneurs to later make much needed adjustments. Thus, one implication of the study is that this practice may have a counterproductive result, suggesting it be modified.
Our study's results suggest entrepreneurs might use modified forms of planning, such as customer development (Blank, 2013). Customer development utilizes the business model canvas (BMC), which contains nine sections including, but not limited to, value proposition, customer segment, venture activities, and revenue stream. These parts come together to form a tentative startup idea. Most importantly, entrepreneurs explicitly state their assumptions about each part in the form of hypotheses. Then, the entrepreneurs talk to a large number of people to explore assumptions and form new hypotheses based upon feedback. The system is likely to increase flexibility for two reasons. First, it emphasizes that initial hypotheses are more likely to be wrong than right, creating the expectation that they will be disconfirmed. Second, the system stresses that the entrepreneur is likely to uncover new information that is more likely to lead to success. This removes much of the motivation to confirm the current hypothesis.

Other methods, including the lean startup process (Ries, 2011), critical assumption planning (Sykes \& Dunham, 1995), and real options planning (McGrath, 1999), encourage entrepreneurs to delay developing detailed plans until they have made assumptions explicit, tested them and, when needed, modified them. Unlike customer discovery, though, the methods test the veracity of their assumptions by trying to get potential customers to take actions that reflect some part of the buying process. By quickly and inexpensively getting an early market reaction, entrepreneurs may generate disconfirming feedback that is too salient to ignore.

In addition to indicating that these multi-step planning systems might be appropriate, this study's findings also suggest that entrepreneurs might benefit by using stand-alone techniques to minimize confirmation bias and overconfidence (Simon et al., 2011). One such technique is devil's advocacy (Russo \& Schoemaker, 1992). To implement devil's advocacy, one person, regardless of his or her true beliefs, advocates for one side of an argument, whereas another person takes the other side. This process generates debate, which, in turn, might lead to more accurate beliefs. Another recommended technique is counterfactual thinking (Trevelyan, 2007). Counterfactual thinking requires entrepreneurs to actively envision ways in which their assumptions might be incorrect. They strive to answer questions such as: In what way might I be wrong? What information contradicts my beliefs? Do I need more data to be sure of my conclusion? By asking these questions, entrepreneurs are encouraged to lower overconfidence and increase flexibility.

Other techniques to reduce overconfidence are simple. For example, entrepreneurs can list every reason they can think of that supports their conclusions as well as every rea- 
son that refutes it (Chen, Simon, Kim, \& Poploskie, 2015). Having entrepreneurs explain their beliefs to others also can be an effective tool (Arkes, Christensen, Lai, \& Blumer, 1987). Finally, if entrepreneurs explicitly recall times when they were incorrect, they will be more responsive to disconfirming evidence (Zacharakis \& Shepherd, 2001).

We believe external organizations can help spur entrepreneurs to use these techniques (Simon et al., 2000). For example, Small Business Development Centers can guide entrepreneurs through these new planning processes, and entrepreneurship teachers can devote semester-long courses to them. Furthermore, the government can fund programs that incorporate these approaches (Blank, 2013). Outsiders also can facilitate the use of specific stand-alone techniques. Funders can dictate that entrepreneurs use them, or even actively participate, for example, by playing devil's advocate. Instructors can teach the techniques and have student use them often enough that the techniques become second nature. Some scholars (e.g., Sharma \& Shakeeel, 2015) even suggest semester-long foundation courses entirely devoted to instilling these tools. While many questions remain about the relationship among overconfidence, decision making processes and flexibility, we believe this paper represents a valuable first step.

\section{References}

Anderson, B. H., \& Maletta, M. J. (1999). Primacy effects and the role of risk in auditor belief-revision processes. Auditing, 18(1), 75-89.

Arkes, H., Christensen, C., Lai, C., \& Blumer, C. (1987). Two methods of reducing overconfidence. Organizational Behavior and Human Decision Processes, 39(1), 133-144.

Ashton, R., \& Ashton, A. (1990). Evidence-responsiveness in professional judgment: Effects of positive versus negative evidence and presentation mode. Organizational Behavior and Human Decision Process, 46, 1-19.

Astebro, T., Jeffrey, S. A., \& Adomdza, G. K. (2007). Inventor perseverance after being told to quit: The role of cognitive biases. Journal of Behavioral Decision Making, 20(3), 253-272.

Barnes, J. H., Jr. (1984). Cognitive biases and their impact on strategic planning. Strategic Management Journal, 5, 129-137.

Blank, S. (2013). Why the lean start-up changes everything. Harvard Business Review, 91(5), 64-72.

Brinckmann, J., Grichnik, D., \& Kapsa, D. (2010). Should entrepreneurs plan or just storm the castle? A meta-analysis on contextual factors impacting the business planning-performance relationship in small firms. Journal of Business Ventur- ing, 25(1), 24-40.

Busenitz, L. W., \& Barney, J. B. (1997). Biases and heuristics in strategic decision making: Differences between entrepreneurs and entrepreneurs in large organizations. Journal of Business Venturing, 12(1), 9-30.

Chen, T., Simon, M., Kim, J., \& Poploskie, B. (2015). Out of the building, into the fire: An analysis of cognitive biases during entrepreneurial interviews. New England Journal of Entrepreneurship, 18(1), 59-70.

Comegys, C. (1976). Cognitive dissonance and entrepreneurial behavior. Journal of Small Business Management, 14(1), 1-6.

Dane, E. (2010). Reconsidering the trade-off between expertise and flexibility: A cognitive entrenchment perspective. Academy of Management Review, 35(4), 579-603.

Davidsson, P., \& Wahlund, R. (1992). A note on the failure to use negative information. Journal of Economic Psychology, 13(2), 343-353.

Fischhoff, B., Slovic, P., \& Lichtenstein, S. (1977). Knowing with certainty: The appropriateness of extreme confidence. Journal of Experimental Psychology: Human Perception and Performance, 3(4), 552564.

Forbes, D. (2005). Are some entrepreneurs more overconfident than others? Journal of Business Venturing, 20(5), 623-640.

Furr, N. R., Cavarretta, F., \& Garg, S. (2012). Who changes course? The role of domain knowledge and novel framing in making technology changes. Strategic Entrepreneurship Journal, 6(3), 236-256.

Gielnik, M. M., Spitzmuller, M., Schmitt, A., Klemann, D. K., \& Frese, M. (2015). "I put in effort, therefore I am passionate": Investigating the path from effort to passion in entrepreneurship. Academy of Management Journal, 58(4), 1012-1031.

Griffin, D. W., \& Varey, C. A. (1996). Towards a consensus on overconfidence. Organizational Behavior and Human Decision Processes, 65(3), 227-231.

Harvey, N., \& Fischer, I. (1997). Taking advice: Accepting help, improving judgment, and sharing responsibility. Organizational Behavior and Human Decision Processes, 70(2), 117-133.

Haynie, J. M., Shepherd, D. A., \& Patzelt, H. (2012). Cognitive adaptability and an entrepreneurial task: The role of metacognitive ability and feedback. Entrepreneurship Theory and Practice, 36(2), 237-265.

Hayward, M. L. A., Shepherd, D. A., \& Griffin, D. (2006). A hubris theory of entrepreneurship. Management Science, 52(2), 160-172.

Higgins, E. T. (1996). Knowledge activation: Accessibility, applicability, and salience. In E. T. Higgins \& A. W. 
Kruglanski (Eds.), Social psychology: Handbook of basic principles (pp. 133-168). New York: Guilford.

Houghton, S. M., Simon, M., Aquino, K., \& Goldberg, C. B. (2000). No safety in numbers: Persistence of biases and their effects on team risk perception and team decision making. Group \& Organization Management, 25(4), 325-353.

Jonas, E., Schulz-Hardt, S., Frey, D., \& Thelen, N. (2001). Confirmation bias in sequential information search after preliminary decisions: An expansion of dissonance theoretical research on selective exposure to information. Journal of Personality and Social Psychology, 80(4), 557-571.

Kahneman, D., \& Lovallo, D. (1993). Timid choices and bold forecasts: A cognitive perspective on risk taking. Management Science, 39(1), 17-32.

Kardes, F. R., Kim, J., \& Lim, J. (1994). Moderating effects of prior knowledge on the perceived diagnosticity of beliefs derived from implicit versus explicit product claims. Journal of Business Research, 29(3), 219225.

Keh, H. T., Foo, M. D., \& Lim, B. C. (2002). Opportunity evaluation under risky conditions: The cognitive process of entrepreneurs. Entrepreneurship Theory and Practice, 27(2), 125-148.

Kiesler, S., \& Sproull, L. (1982). Managerial response to changing environments: Perspectives on problem sensing from social cognition. Administrative Science Quarterly, 27(4), 548-570.

Klayman, J., Soll, J., Gonzalez-Vallejo, J., \& Barlas, S. (1999). Overconfidence: It depends on how, what, and whom you ask. Organizational Behavior and Human Decision Processes, 79(3), 216-247.

Lau, A. Y. S., \& Coiera, E. W. (2006). A Bayesian model that predicts the impact of web searching on decision making. Journal of the American Society for Information Science and Technology, 57(7), 873-880.

Mahajan, J. (1992). The overconfidence effect in marketing and management predictions. Journal of Marketing Research, 34, 329-342.

Mannes, A. E. (2009). Are we wise about the wisdom of crowds? The use of group judgments in belief revision. Management Science, 55(8), 1267-1279.

McGrath, R. G. (1999). Falling forward: Real options reasoning and entrepreneurial failure. Academy of Management Review, 24(1), 13-30.

McMillan, J. J., \& White, R. A. (1993). Auditors' belief revisions and evidence search: The effect of hypothesis frame, confirmation bias, and professional skepticism. The Accounting Review, 68(3), 443-465.

McNamara, G., \& Bromiley, P. (1997). Decision making in an organizational setting: Cognitive and organiza- tional influences on risk assessment in commercial lending. Academy of Management Journal, 40(5), 1063-1088.

Moulton, B. R. (1990). An illustration of a pitfall in estimating the effects of aggregate variables on micro units. The Review of Economics and Statistics, 72(2), 334-338.

Nicholls-Nixon, C., Cooper, A. C., \& Woo, C. Y. (2000). Strategic experimentation: Understanding change and performance in new ventures. Journal of Business Venturing, 15(5), 493-521.

Nickerson, R. S. (1998). Confirmation bias: A ubiquitous phenomenon in many guises. Review of General Psychology, 2(2), 175-220.

Oskamp, S. (1965). Overconfidence in case-study judgments. Journal of Consulting Psychology, 29(3), 261-265.

Parker, S. (2006). Learning about the unknown: How fast do entrepreneurs adjust their beliefs? Journal of Business Venturing, 21(1), 1-26.

Ries, E. (2011). The lean startup: How today's entrepreneurs use continuous innovation to create radically successful businesses. New York: Crown Business.

Robinson, A. T., \& Marino, L. D. (2015). Overconfidence and risk perceptions: Do they really matter for venture creation decisions? International Entrepreneurship and Management Journal, 11(1), 149-168.

Russo, J. E., \& Schoemaker, P. J. H. (1992). Managing overconfidence. Sloan Management Review, 33(2), 7-17.

Schwenk, C. R. (1995). Strategic decision making. Journal of Management, 21(3), 471-493.

Sharma, V., \& Shakeel, M. (2015). Illusion versus reality: An empirical study of overconfidence and self attribution bias in business management students. Journal of Education for Business, 90(4), 199-207.

Shepherd, D. A. (2015). Party on! A call for entrepreneurship research that is more interactive, activity based, cognitively hot, compassionate, and prosocial. Journal of Business Venturing, 30(4), 489-507.

Simon, M., \& Houghton, S. M. (2003). The relationship between overconfidence and the introduction of riskier products: Evidence from a field study. Academy of Management Journal, 46(2), 139-149.

Simon, M., Houghton, S., \& Savelli, S. (2003). Out of the frying pan...? Why small business managers introduce high risk products. Journal of Business Venturing. 18(3), 419 - 440.

Simon, M., \& Shrader, R. C. (2012). Entrepreneurial actions and optimistic overconfidence: The role of motivated reasoning in new product introductions. Journal of Business Venturing, 27(3), 291-309. 
Simon, M., Houghton, S. M., \& Aquino, K. (2000). Cognitive biases, risk perception, and venture formation: How individuals decide to start companies. Journal of Business Venturing, 15(2), 113-134.

Simon, M., Kim, J., Houghton, S. M., \& Deng, X. (2011). When it's right to be "wrong": The effects of overconfidence and planning on product performance in a dynamic environment. Journal of Small Business Strategy, 22(1), 21-46.

Soll, J. (1996). Determinants of overconfidence and miscalibration: The roles of random error and ecological structure. Organizational Behavior and Human Decision Processes, 65(2), 117-137.

Soll, J. B., \& Larrick, R. (2009). Strategies for revising judgment: How (and how well) people use others' opinions. Journal of Experimental Psychology: Learning, Memory, and Cognition, 35(3), 780-805.

Subbotin, V. (1996). Outcome feedback effects on underand overconfident judgments (general knowledge tasks). Organizational Behavior and Human Decision Processes, 66(3), 268-276.

Sykes, H. B., \& Dunham, D. (1995). Critical assumptions planning: A practical tool for managing business development risk. Journal of Business Venturing, 10, 413-424.

Tan, W., Tan, C., \& Teo, H. (2012). Consumer-based decision aid that explains which to buy: Decision confirmation or overconfidence bias? Decision Support Systems, 53(1), 127-141.

Trevelyan, R. (2007). Optimal optimism. Business Strategy Review, 18(3), 18-22.

Trevelyan, R. (2008). Optimism, overconfidence and entrepreneurial activity. Management Decision, 46(7), 986-1001.

Walsh, J. P. (1995). Managerial and organizational cognition: Notes from a trip down memory lane. Organization Science, 6(3), 280-321.

Wyer, R. S. (2008). The role of knowledge accessibility in cognition and behavior: Implications for consumer information processing. In C. P. Haugtvedt, P. M. Herr, \& F. R. Kardes (Eds.), Handbook of Consumer Psychology (pp. 31-76). New York: Psychology Press.

Yaniv, I. (2004). Receiving other people's advice: Influence and benefit. Organizational Behavior and Human Decision Processes, 93(1), 1-13.

Yates, J. F., Lee, J., Shinotsuka, H., Patalano, A. L., \& Sieck, W. R. (1998). Cross cultural variations in probability judgment accuracy: Beyond general knowledge overconfidence? Organizational Behavior and Human Decision Processes, 74(2), 89-117.

Zacharackis, A. L., \& Shepherd, D. A. (2001). The nature of information and overconfidence on venture capi- 23 talists' decision making. Journal of Business Venturing, 16(4), 311-333.

\section{Appendix A: Measures}

\section{Overconfidence}

1) In 2008, what percent of software development projects were over budget?
A) Less than $55 \%$
B) More than $60 \%$

How confident were you of your previous answer? (Write a number between 50 and 100)

2) What percent of U.S. small businesses had a website in September of 2008?
A) Less than $50 \%$
B) More than $60 \%$

How confident were you of your previous answer? (Write a number between 50 and 100)

3) What was the INTERNATIONAL Internet growth (in total number of users) from March of 2007 to March of 2008 ?

A) Less than $\mathbf{3 0 0}$ million new users worldwide

B) More than 350 million new users

How confident were you of your previous answer? (Write a number between 50 and 100)

\section{Controls}

Optimism. (Scale ranges from $1=$ Strongly agree to $5=$ Strongly disagree).

1. In uncertain times, I usually expect the best.

2. If something can go wrong for me, it will. Reverse coded.

3. I'm always optimistic about my future.

4. I hardly ever expect things to go my way. Reverse coded.

5. I rarely count on good things happening to me. Reverse coded.

6. Overall, I expect more good things to happen to me than bad. 


\section{Domain expertise.}

1. How many college-level courses have you taken that related to either new product introductions or web marketing?

2. To what extent do you have work experience related to either new product introduction and/or web marketing? (Scale ranges from $1=$ None to $5=$ To an extremely large extent)

\section{Entrepreneurial intent.}

Should Anduro Marketing launch their new product?

(Scale ranges from 1 = Definitely not to 5 = Definitely yes) 